\title{
Genes for adaptation and learning spanning evolution: computational comparison between synaptic transmission and chemo-tactic signaling protein networks
}

\author{
Riham Satti ${ }^{1}$, Gillian Deakin ${ }^{1}$, Reiko J Tanaka ${ }^{1,2}$, Aldo Faisal ${ }^{1,3^{*}}$ \\ From Twentieth Annual Computational Neuroscience Meeting: CNS*2011 \\ Stockholm, Sweden. 23-28 July 2011
}

Plasticity at the synapse and adaptation in bacterial chemotaxis are two prominent examples of biological regulation and signal processing in response to noisy, time-varying stimuli $[1,2]$. Both regulatory systems process glutamate stimuli (as neurotransmitter and food respectively) to determine whole-cell response to future changes in glutamate concentration. These two evolutionary distant protein networks thus perform a common computational function (adaptation to stimulus patterns) on glutamatergic inputs. Moreover, the bacterial glutamate receptor is an evolutionary ancestor of mGlu and NMDA receptors in the mammalian synapse $[1,3]$. Thus, we were curious if common regulatory principles of both networks and specifically if their proteins had common evolutionary roots. We investigated this hypothesis by performing a comparative bioinformatics study to test if the amino acid sequences of these two protein networks are conserved across 600 Million years.

We focussed on mouse (M. Musculus) post-synaptic proteins [4] and the 23 proteins involved in bacterial chemotaxis of E.coli $[2,5]$, both available on the UniProt protein database. We measured protein similarity by aligning the sequences of all synaptic M.Musculus proteins (tagged as "synapse" related in UniProt) with all 23 bacterial chemotaxis proteins, using the local pairwise Smith-Waterman algorithm [6]. Because the algorithm's similarity score is sequence length dependent and evolutionary distance between proteins results in considerable genetic drift, the comparison is difficult [7]. Therefore,

\footnotetext{
* Correspondence: aldo.faisal@imperial.ac.uk

'Department of Bioengineering, Imperial College London, London, SW7 2AZ, UK

Full list of author information is available at the end of the article
}

we developed a normalization method to establish significance of alignments (cf. Figure): We established two baseline sets of alignments: we aligned 300 generic (non-synpatic) proteins from M.Musculus (with similar length as the synaptic proteins) with the 23 bacterial chemotaxis proteins and vice versa 100 generic (non chemo-tactic) E.coli proteins (of similar length as the chemo-tactic proteins) with the 84 synpatic proteins from M.Musculus. Any significant sequence similarity score between synaptic and chemotactic proteins would have to stands out from the large set of scores of the baseline sets: We normalised the alignment score $S_{\mathrm{ij}}$, between a synaptic protein $i$, and a chemo-tactic protein $j$, using the mean $\mu_{\mathrm{ij}}$, and standard deviation $\sigma_{\mathrm{ij}}$ of the baseline score distributions. Thus, alignments between synaptic and chemo-tactic proteins with positive normalized scores, indicated strong sequence similarity.

We found a set of a dozen synaptic and chemotactic proteins that show high sequence similarity across this vast evolutionary gap. The highest scoring one was, for example, the methyl-accepting chemotaxis protein III in bacteria and the glutamate receptor interacting 1 (GRIP1) associated protein in synaptic transmission. GRIP1 is an adapter protein linking AMPA receptors associated to increase synaptic efficiency [8], whereas methyl-accepting chemotaxis protein III is involved in adaptation by varying the level of methylation to allow bacteria to remain sensitive to changes in average glutamate concentration [9]. This novel link suggests regulatory networks for adaptation and learning at the synapse have common ancestors and possible common principles (see also [10]). We pose the idea, that like Mitochondria (which were bacteria integrated into 
eukaryotic cells to supply energy) so could 'learning' at the chemical synpase be the result of integrating the chemotaxis network into early neurons.

\section{Acknowledgements}

RS and GD contributed equally to this work.

\section{Author details}

'Department of Bioengineering, Imperial College London, London, SW7 2AZ, UK. ${ }^{2}$ Institute for Mathematical Sciences, Imperial College London, London,

SW7 2AZ, UK. ${ }^{3}$ Department of Computing, Imperial College London, London, SW7 2AZ, UK.

Published: 18 July 2011

\section{References}

1. Ryan TS, Grant SGN: The origin and evolution of synapses. Nature Rev Neurosci 2009, 10:701-712.

2. Bray $\mathrm{D}$, Levin MD, Lipkow K: The chemotactic behavior of computerbased surrogate bacteria. Curr Biol 2007, 17:12-19.

3. Hille B: Ion Channels of Excitable Membranes. Massachusetts: Sinauer Associates; 3 2001, 721.

4. Hayer A, Bhalla S: Molecular switches at the synapse emerge from receptor and kinase traffic. PLoS Computational Biology 2005, 1(2):137-152.

5. Wadhams GH, Armitage JP: Making sense of it all: Bacterial chemotaxis. Nature Rev Mol Cell Biol 2004, 5:1024-1037.

6. Smith TF, Waterman MS: Identification of common molecular subsequences. J Mol Biol 1981, 147:195-197.

7. Brenner SE, Chotia C, Hubbard TJP: Assessing sequence comparison methods with reliable structurally identified distant evolutionary relationships. PNAS 6073, 95:6078.

8. Dong H, et al: GRIP: a synaptic PDZ domain-containing protein that interacts with AMPA receptors. Nature 1997, 386:279-284.

9. Engström P, Hazelbauer GL: Multiple methylation of methyl-accepting chemotaxis proteins during adaptation of E. coli to chemical stimuli. Cell 1980, 20:165-171.

10. Gestwicki JE, et al: Evolutionary Conservation of Methyl-Accepting Chemotaxis Protein Location in Bacteria and Archaea. J Bacteriol 2000 182:6499-6502.

doi:10.1186/1471-2202-12-S1-P97

Cite this article as: Satti et al:: Genes for adaptation and learning spanning evolution: computational comparison between synaptic transmission and chemo-tactic signaling protein networks. BMC

Neuroscience 2011 12(Suppl 1):P97.

\section{Submit your next manuscript to BioMed Central and take full advantage of:}

- Convenient online submission

- Thorough peer review

- No space constraints or color figure charges

- Immediate publication on acceptance

- Inclusion in PubMed, CAS, Scopus and Google Scholar

- Research which is freely available for redistribution

Submit your manuscript at www.biomedcentral.com/submit
C Biomed Central 